\title{
IS THERE AN ALTERNATIVE?
}

\begin{abstract}
One of the main recommendations of the Porritt Report ${ }^{1}$ was the creation of area health boards-authorities which would be responsible for the administration and co-ordination of all the medical services in any one area. In the report's view, "the preventive and personal health services can only be effectively integrated with the family doctor and hospital services by transferring them (services and staff) to the area health boards." At present a Royal Commission is considering the future structure of local government in England, while the Seebohm Committee is considering the future of some of the local authority services. In her article Miss Elizabeth Burney considers the possible relevance of changes in local government to some suggested changes in the health services.
\end{abstract}

\section{Local Government Reform and the Health Services}

\author{
ELIZABETH BURNEY, M.A., B.LITT.*
}

Brit. med. F., 1967, 3, 41-42

By the end of 1968 a Royal Commission will have published its blueprint for modernizing the structure and functions of local government in England (a separate commission sits for Scotland; Wales, for rather inadequate reasons, has been excluded). By the mid-1970's there is every chance that a profoundly reformed system will be in operation. Naturally the size and utility of the local authority health department is being reviewed along with everything else. But, still more important for the health services as a whole, the new structure could provide the long-discussed but little-sought opportunity for unifying the three branches comprising hospitals, general practice, and the community health services. The key point is that this could now take place under local authority leadership, instead of local government merely running the third branch, as it does at present.

This may at first seem far removed from local government reform, which is concerned in the first place with the optimum size of the elected unit. But size is meaningless unless related to functions ; indeed, one very obvious difficulty is that each separate function of local government might ideally operate under slightly different circumstances, so that every solution is something of a compromise. But the pattern that is expected to emerge is likely to be similar to that already established in Greater London (also excluded from the current review). Large "first tier" authorities will probably deal with such things as town planning, transport, education, and possibly housebuilding. Within these areas smaller "second tier" authorities would deal with more localized community services, such as welfare, parks, and refuse collection.

\section{"Regional ". Units}

What size would these new authorities be likely to be ? It is fashionable to talk of the largest units as "regional," but this word means different things to different people. Some people (including myself) would prefer these to be as large as possible, so that they would not be many more in number than the present economic planning regions-perhaps only a dozen in the whole of England and Scotland. Others (including officials

* Staff writer, The Economist at the Ministry of Housing and Local Government) have been encouraging the Royal Commission to think in terms of the largest unit being keyed to the major cities and their hinterlands, in a scheme which might eventually produce outside London 20 to 30 "city regions," each averaging over two million people. In any case the actual population size in relation to area is likely to vary widely in different parts of the country. The second-tier authorities are also bound to vary in size, but it is likely to be agreed that for effective contact with their populations they will have to be considerably smaller than the 200,000population London boroughs. In country areas ease of communications rather than numbers of people served might be the governing factor.

The purpose of all this is not only to increase efficiency but to strengthen local democracy by creating local councils which can be seen to be functioning in a way that is relevant to the needs of modern society. This must mean, among other things, that local authorities regain some of their independence from trivial administrative control from Whitehall (though not from effective quality control), together with the financial means to exercise that independence. For example, it has been argued that petrol tax should be levied by local rather than central government, or that local authorities should levy a sales tax. All this and much more becomes credible once the mass of dead wood hampering the present system has been hacked away.

The relevance to the health services becomes more obvious once one starts to look at the kind of functional and organizational changes which the Royal Commission is likely to consider. Already another committee (like the Royal Commission, under the chairmanship of Sir John Maud) has reported on the "management" of local authorities. It has recommended the abolition of government by departmental committee in favour of a single management committee for determining the main lines of policy in all fields, to be advised by specialist committees. Once this was achieved (and it could take place with or without any structural changes in the authorities as a whole) the traditional career structure of the "professional" local government officers within specialist departments would become less rigid. For, though specialists would still be greatly needed, they would not need to be organized to fit the particular group of jobs allotted to a policy committee, but could be more sensibly grouped according to functions or skills. 


\section{Seebohm Committee}

As an example of this-and one which directly affects the health services-yet another committee (the Seebohm Committee) is currently considering the future of the local authority "personal and allied services." It is likely to recommend that social workers, whose skills are in demand in many different fields but whose clients may often be the same people with different "problems," should form a separate social work department within the local authority, servicing other departments where necessary. Once this possibility is admitted there is no particular reason why hospital social workers should not also be part of the same or a related organization.

Similarly, housing is a subject which at present involves several different departments: the housing department itself, and the departments dealing with health, architecture, and planning. Yet no one could seriously claim that public health, in the Victorian sense, any longer has a major role in deciding which house should be demolished. Far better concentrate the whole process of building and redevelopment in a single department, which should probably be part of the first-tier authority (there is a good case for making the allocation and management of housing into a second-tier function).

In the course of reorganization, therefore, it looks as if the medical officer of health could lose his responsibility both for housing and for social workers, including the entire welfare set-up. Why indeed should the few remaining traditional responsibilities of the medical officer of health-midwives, health visitors, and a hodge-podge of sanitary and statistical responsibilities-remain as they are ? If the health department as we know it disappeared the way would be open for a much more realistic allocation of professional, technical, and administrative responsibility in the health and allied services as a whole.

\section{Area Health Boards}

Radical reorganization is no new idea. Back in 1962 the committee appointed by the medical profession to review the medical services (the Porritt Committee) ${ }^{1}$ strongly recommended unified control of the three branches of the health service. They proposed that the existing structure should be replaced by area health boards, to which all doctors and health employees should be contracted. Subsidiary professional committees, they suggested, should be responsible for general medical services, for hospitals, and for preventive and social health services. They envisaged that the only bodies that would remain outside (though linked to) the system would be the teaching hospitals. But, because no new health role was suggested for the local authority itself, the committee had to propose a rather awkward solution for the medical officer of health. He should, they said, become the head of a hospital department of social health staffed by health visitors, social workers, and midwives, and be responsible to the area health board. Nevertheless, he should remain responsible to the local authority for "environmental health and hygiene."
There was a great deal of sense in these proposals, but one noticeable omission. Rightly anxious to free the area health services from petty Whitehall interference, nothing in the way of democratic control was proposed to take its place, other than a vague reference to "capable and public-spirited individuals" on the area health boards. Inevitably the impression was given of a system proposed by doctors for doctors. Yet there can be no doubt that health is properly a subject of both local and national democracy. For one thing, a great many decisions concern a choice of public investment-should not a community have a say in whether to build a health centre or provide more kidney machines ? Or whether to build more houses, or to provide more maternity beds for people living in poor conditions? An elected body may respond much more readily than a hospital or an independent board to demands from the community itself-for instance, local government has on the whole been much readier than the hospital service to provide child guidance clinics.

It should not in fact be difficult to fit a unified health service directly into the reformed local government structure, substituting for the vaguely autonomous arca health boards of the Porritt proposals direct control by the local authorities themselves. The likelihood of a two- (or even three-) tier structure of local government should make this easier-for instance, the major hospitals (including the teaching hospitals, since there is no good reason to exclude them) could be controlled by regional units of local government instead of by the present regional hospital boards. Small local hospitals might fit better into the second-tier functions of local government. At all levels community and medical services could be better linked-thus general practice could suitably become a branch of the lowertier authorities, the basic unit for all the personal health and welfare services. Public investment could be channelled into group practices, health centres, or Porritt-type departments of social health in hospitals according to the needs of the areas concerned.

More scope could be given to professional administrators to obtain top jobs in the community health services for which the medical profession is not necessarily more suited than any other. Much more scope could be given to doctors, particularly general practitioners, to develop new forms of community care with the full backing of the local authority's hospitals, social workers, and elected representatives. Whether there would still be anybody called the medical officer of health, or what his status would be, matters very little. What does matter is that the system should give doctors every opportunity to develop all branches of the health services in response to real needs, as well as developing the means of finding out what those needs may be. Local government reform could surely provide the opportunity for a better distribution of resources and better support to doctors and their patients.

\section{RERERENCB}

1 A Review of the Medical Services in Great Britain, 1962. London. 